
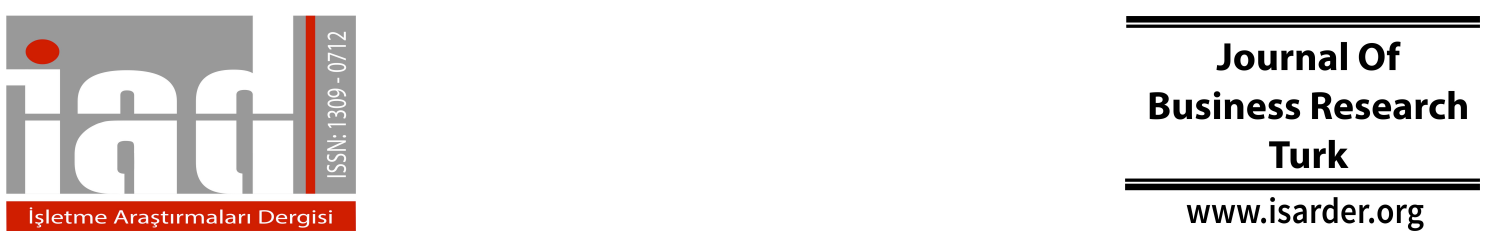

\title{
The Effect of Psychological Empowerment on Organizational Silence in Hotels
}

$\begin{array}{ccc}\text { Ali AVAN } & \text { Özcan ZORLU } & \text { Ahmet BAYTOK } \\ \text { Afyon Kocatepe University } & \text { Afyon Kocatepe University } & \text { Afyon Kocatepe University } \\ \text { Faculty of Tourism, Tourism } & \text { Faculty of Tourism, Tourism } & \text { Faculty of Tourism, Tourism } \\ \text { Management Department } & \text { Guidance Department } & \text { Management Department } \\ \text { Afyonkarahisar, Turkey } & \text { Afyonkarahisar, Turkey } & \text { Afyonkarahisar, Turkey } \\ \text { aliavan@aku.edu.tr } & \underline{\text { ozcanzorlu@aku.edu.tr }} & \underline{\text { ahmetbaytok@aku.edu.tr }}\end{array}$

Abstract

The aim of this study is to determine whether psychological empowerment (PE) is related with or have any effects on organizational silence (OS) in hotel enterprises. Relevant data was collected via questionnaire forms from 348 employees of five star hotels operating in Antalya. To test the hypothesis of the study Correlation and Regression Analyses were performed. Findings of the study basically indicate that PE applications have relatively weak effect on OS. The results show that only selfdetermination dimension of PE has a significant effect on OS, while the other dimensions have no effect on OS.

Keywords: Psychological Empowerment, Organizational Silence, Voice Behaviour.

\section{Introduction}

Globalization, technological development and high customer expectations forces today's organizations to have much more expectations from their employees. Nowadays, work environment requires to employees who take more initiatives, exhibit their creativeness much more and taking more responsibility rather than traditional command and control hierarchy (Quinn and Spreitzer, 1997: 37). Employee empowerment (EE) has become one of the popular issues as a necessity of those radical changes. Notions of empowerment are derived from theories of participative management and employee involvement (Spreitzer, Kizilos and Nason, 1997: 680). And, there are numerous reasons making EE the point of interest at organizational level, such as being the main factor that providing organizational and managerial effectiveness, enhancing productive organizational power and efficiency by sharing of power and control with followers, and essential importance of EE techniques at group development and team building (Conger and Kanungo, 1988: 471; Klagge, 1998: 549; Appelbaum, Hebert and Leroux, 1999: 234). Empowerment has two main approaches: structural and psychological (Chan, Taylor and Markham, 2008). While the structural approach of empowerment focuses on managerial action (Menon, 2001), psychological empowerment (PE) focuses on employees' motivation (Kim et al., 2012: 11). The 
mainly emphasized approaches of empowerment is PE which is characterized with authority that providing to make decisions of each employees without executive's approval and be able to speak up their concerns as a result of sharing of the power with employees (Conger and Kanungo, 1988).

Employee silence (ES) is a behavior, avoiding to share of any ideas, suggestions or concerns about individuals, products or processes with others, that are normally need to be stated (Kish-Gephart et al., 2009: 163). Milliken et al., (2003) assert that organizational silence (OS) occur for a variety of reasons such as labelling, alienation fear, worrying about interruption of organizational relations and thinking that speak up is nonsense. Labelling here refers to being blacklisted of an employee with tattletale, troublemaker and complainer in case of speaking up the problems about organizational issues. Besides, silence also occurs from personally lack of experience and tenure, hierarchical structure, unsupportive culture and weak/inadequate relation with the executive. Demir (2014: 1108) further states that silence behaviour could be the result of insensitivity and carrier expectations. Employees who cannot embrace unfair attitudes could stay silent toward their self-interests arising from their carrier expectations. These reasons revealing silence in organizations can be prevented by PE efforts. Individuals who believe that they will not incur from any threat or un-solicited situation when they speak up, could avoid from OS behaviour by feeling more confident in case of they make a stride fairly and determinedly in the organization. More broadly, this type of behaviours will lead long term outcomes such as intention to stay, low turnover rate, high organizational satisfaction and commitment.

In the hotel industry, where service quality has become essential, proper management of the human element has become critical (Jha and Nair, 2008: 147). One of the most important features of service is inseparability, which requires face to face interaction between customer and employees. This feature of services make essential for the employees to act in freedom and make fast decisions at service practices. Therefore employee empowerment considered as one of the key components of providing better customer service in hospitality industry (Hancer and George, 2003: 5). Employees have an important role at service providing, and their understandings about how much they harmonize the work with their abilities and how much they have influence on strategic decisions is also important in terms of service process improvements. Moreover, getting organizational advantages from this role is only possible in case of existing psychologically empowered employees and building a transparent/healthy relationship network whereby participation to decisions is provided. And, mutual interaction and communication underpins of this network. Thus, Guchait et al (2016: 460) emphasize that one of the antecedents of organizational learning at hotel enterprises is interpersonal communication, and, this communication has a mediating role between perceived differences about organizational climate and organizational learning relations. Likewise, Koyuncu et al. (2013) state that employees avoiding from silence are more committed to organization and improve longer-term relations with their employers.

The aim of this study is to determine the role of PE efforts at decreasing OS. This role discussed with PE and its sub-dimensions. Thus, firstly PE and OS concepts is explained in detail, then relationship between PE and OS is tried to reveal depending on existing literature. Afterwards, meaning, competence, self-determination and impact sub-dimensions of PE is described and lastly it is determined that which PE subdimension is more important at preventing OS behaviour of employees. 


\section{Conceptual Framework}

\subsection{Psychological Empowerment}

PE is very complex and refers to different meanings for different people (Quinn and Spreitzer, 1997: 37), basically expresses the sharing power with the followers (Conger and Kanungo, 1988: 473) or an authority that is consisting of an employee's decision making without any approvals at his/her work. PE is derived from power and control notions (Conger and Kanungo, 1988). Besides, in the majority of today's work, organizations delegation of responsibilities by executives is being perceived as PE faultily (Conger and Kanungo, 1988; Conger, 1989; Quinn and Spreitzer, 1997). Empowerment is not a set of management practices, but rather an individual mind-set (Quinn and Spreitzer, 1997: 44). Empowerment is fundamentally a motivational process of an individual's experience of feeling enabled (Corsun and Enz, 1999: 205). In other words, PE is a process that includes strengthening and altering inner believes by perceiving personal competence (Conger, 1989: 18). As Menon (2001: 159) emphasizes the root of the empowerment construct is the concept of employee experienced power. Empowerment includes organizational processes and structures that enhance member participation and improve goal achievement for the organization (Perkins and Zimmerman, 1995: 571).

Empowerment is defined by Conger and Kanungo (1988: 474) as a process of enhancing feelings of self-efficacy among employees. In this process employees identify the conditions that foster powerlessness and remove those conditions by both formal organizational practices and informal techniques of providing efficacy information. In that, they consider empowerment as the motivational concept of selfefficacy. Moreover, Thomas and Velthouse (1990) argued that empowerment is multifaceted. Thus, its essence cannot be captured by a single concept (Spreitzer, 1995: 1443). Thomas and Velthouse (1990: 668) defined empowerment in terms of intrinsic motivation. Intrinsic task motivation involves positively valued experiences that individuals derive directly from a task.

Empowerment is separated into two main approaches: structural which is also called as relational and psychological (Chan, Taylor and Markham, 2008: 445; Gkorezis, Hatzithomas and Petridou, 2011). The structural approach of empowerment generally focuses on managerial action and involves changes in structural conditions through power sharing or granting of power and decision making authority (Menon, 2001). On the other hand motivational or psychological perspective of empowerment emphasizes the employee motivation and focuses on an employee's subjective commentaries of organizational environments (Kim et al., 2012: 11). Individuals in organizations make a variety of assessments or judgments with respect to specific tasks. Four dimensions of assessment are included as cognitive components of intrinsic motivation impact, competence, meaningfulness and choice (Thomas and Velthouse, 1990: 671). Spreitzer (1995) also defined PE as motivational construct in four cognitions: meaning, competence, self-determination and impact. Menon (2001: 161) expressed PE from the perspective of the state of mind of the empowered individual and defined PE as a cognitive state characterised by a sense of perceived control, competence and goal internalisation.

Meaning as a sub-dimension of PE refers the value of the task goal or purpose, judged in relation to the individuals own ideals or standards. Meaning involves the 
individual's intrinsic caring about a given task (Thomas and Velthouse, 1990: 672). In this assessment there is a fit between the requirements of a work role and beliefs, values and behaviours (Spreitzer, 1995: 1443; Chan, Taylor and Markham, 2008: 445). Within this context employees feel that their work is important to them (Quinn and Spreitzer, 1997: 41). Meaning serves as the "engine" of empowerment (Spreitzer, Kizilos and Nason, 1997).

Competence sub-dimension of PE basically refers to the degree to which a person can perform task activities skilfully when he or she tries (Thomas and Velthouse, 1990: 672). In other words competent employees are confident about their ability to do their work well (Quinn and Spreitzer, 1997: 41; Chan, Taylor and Markham, 2008: 445). Without a sense of confidence in their abilities, individuals will feel inadequate and they will not feel empowered (Spreitzer, Kizilos and Nason, 1997). Spreitzer (1995: 1443) express this dimension as competence rather than self-esteem, because she focused on efficacy specific to a work role rather than on global efficacy.

Another sub-dimension of PE self-determination reflects whether individuals see themselves as the origin of their actions (Spreitzer, Kizilos and Nason, 1997: 682). And, it involves causal responsibility for a person's actions. As Deci and Ryan (1985) noted, the central issue in self-determination is the experience of choice (cited in Thomas and Velthouse, 1990: 673). This means that they are free to choose how to do their work (Quinn and Spreitzer, 1997: 41). If employees believe that they are just following the orders of someone up hierarchy and feel little autonomy or freedom, they will also lack a sense of empowerment (Spreitzer, Kizilos and Nason, 1997: 682).

Impact as the fourth dimension of PE refers to the degree to which behavior is seen as "making a difference" in term of accomplishing the purpose of the task (Thomas and Velthouse, 1990: 672). If any employee empowered at impact sub-dimension he/she believes that he/she can have influence on the work unit (Quinn and Spreitzer, 1997: 41). Impact is the degree to which one can influence strategic, administrative, or operating outcomes at work (Spreitzer, De Janasz, and Quinn 1999: 512; Chan, Taylor and Markham, 2008: 445).

Spreitzer (1995) point out that each dimension is essential for empowerment. Thus, each of them adds a unique element to the overall construct of empowerment. No unidimensional conceptualization of empowerment by itself would capture the full essence of the concept (Spreitzer, Kizilos and Nason, 1997). Relevant dimensions of the empowerment reflect an active, rather than a passive orientation to one's work role. In other words, empowered individuals do not see their work situation as 'given' but rather something able to be shaped by their actions (Spreitzer, De Janasz, and Quinn 1999: 512 ). It is also crucial to state that organic structure, organizational support, access to strategic information, access to organizational resources and organizational culture are identified as social structural antecedents of psychological empowerment (Hancer and George, 2003: 5).

\subsection{Organizational Silence}

OS that enure organizations, generally accepted as a complicated research phenomenon on the occasion of the disclosure of behaviour actually exist. OS attitude is one of the prior organization issues that should be taken into account, since it undermines the enterprise in long term and affects other issues in the organization (Van 
Dyne et al., 2003: 1364). OS creates an undesirable structure that damages all functions of the organization by causing the block all intra-organizational communication channels.

Morrison and Milliken (2000) identify employee silence (ES) as a collective phenomenon in which employees keep back their ideas about potential organization issues. ES is not to sharing out of any ideas, suggestions and concerns related with individuals, products or processes that must be actually shared by perception of authority (Kish-Gephart et al., 2009: 163). ES also can be characterized as not expressing behavioral, cognitive and emotional appraisals of the employees-who are thought to have ability to effect changes and solutions-about intraorganizational practices (Pinder and Harlos, 2001: 334). Beside, organizational voice (OV) is voluntarily expression of the employee ideas about organizational issues. Voluntarily expression of the ideas is important in context of its role on decision process (Banerjee and Somanathan, 2001: 189). Employees, who believe that their ideas will take into consideration, can use this ability for similar conditions they experienced. Premeaux and Bedeian (2003: 1538) define OV as openly stating one's views or opinions about workplace matters, including the actions or ideas of others, suggested or needed changes, and alternative approaches or different lines of reasoning for addressing jobrelated issues.

Although OS and OV are multidimensional concepts, they can be separated in the context of behavioral symptoms, observer qualifications and employee oriented results. If these two concepts are shallowly compared; OS means intentionally avoiding to speak up of any ideas or concerns while OV refers to voluntarily speak up those ideas/concerns. Indeed, voluntarily expressing of any concerns, knowledge and recognitions which contribute to organizational development is the critical component at determining the distinction between these two concepts. Pinder and Harlos (2001) emphasize that OS is an active, conscious and specific intended action which have a particular aim. Thus, OS could be described as a conscious, intentional and purposeful action in which employees withholding the useful knowledge. And, there are three employee specific motivations related with OS and OV: 1) disengaged behaviour based on resignation, 2) self-protective behaviour based on fear, and 3) other oriented behaviour based on cooperation. Additionally, these two concepts are distinct within the context of prosocial behaviour (Van Dyne et al., 2003: 1360).

OS concept is addressed with various dimensions in the existing literature. Van Dyne et al. (2003) conceptualized OS as acquiescent silence, defensive silence and prosocial silence. Acquiescent silence is withholding ideas, knowledge or concerns based on resignation that consisting a more passive behaviour, while defensive silence refers to exhibit same behaviour (withholding the ideas and etc.) based on fear with the biophilia. Meanwhile this type of defensive silence is very similar to Pinder and Harlos's (2001) Quiescence silence in terms of its characteristics. Yet, Quiescence silence basically refers a situation that ideas, knowledge and concerns could not be clearly speak up due to wilful neglecting based on fear. Also, Pinder and Harlos conceptualize OS in two distinctive dimensions named as acoustic and pragmatic silence. Pragmatic silence refers to absence of speech depending upon benefits and strategic purposes while acoustic silence indicates absence of sound-waves. And, prosocial silence consists of a prosocial behaviour that Morrison and Milliken (2000) 
stated as silence culture. Prosocial silence is withholding beneficiary knowledge, ideas and concerns with the aim of altruism.

Although members of the organizations are tend to speak up their ideas about important issues, extended literature implies that members of any organization could keep their silence based on the fear occurring from its possible negative results. Morrison and Milliken (2000: 708) consider OS as an outcome that owes its origins to manager's fear of negative feedback and implicit beliefs held by the managers. Additionally, they state that a systematic silence culture would occur owing to withhold any idea or fact arising from the fear of its negative feedbacks and thinking that it is worthless. Hereunder, OS occurs as a culture that affects all employees attending in the organization. Van Dyne et al. (2003) also emphasize that OS should be considered from the perspective of prosocial behaviour as well as its acquiescent and defensive dimensions. And, Bowen and Blackmon (2003), stress self-reinforcing collective dynamics of voice or silence exist in work groups. Pinder and Harlos (2001) state that OS occurs in individual dimension and employees exhibits OS as a response to perceived injustice. Zhou and George (2001) either have studied individual characteristics of OS.

Individuals need to decide whether to speak up or remain silent about concerns in work environment. This decision choice is made in organizational hierarchy. Individuals who intend to speak up their concerns also recognize that they will be charged by the managers who do not want to hear any problem. And this matter of fact creates tacit knowledge at social systems that is about desire to speak up. Feeling of being unable to speak up cause descent into desperation for employees and induce some negative outcomes such as low work satisfaction, high rate intention to leave, stress and depression (Milliken and Morrison, 2003: 1563). Employees, who are aware of the problems in organization, think that senior managers are not open to real-sincere discussions. Suspicions of employees indicating "senior managers generally avoid to discuss threatening and anxious issues" lie behind this fact (Beer and Eisenstat, 2000: 32).

Perceptions of individuals about other's attitudes towards a fact in work environment, significantly affect OS. Individuals voluntarily speak up their concerns when they believe that other members of the organization appropriate his/her position, otherwise they remain silent. And, this fact creates silence spirals in terms of sharing beneficiary knowledge in the organization and these spirals limit open and sincere discussions that are necessary for organizational development (Bowen and Blackmon, 2003: 1393). Likewise, if individuals perceive any discrimination in the organization, they generally do not reveal this. Enterprises' concerns about not sustaining their existence in the case of employees' speaking up any discrimination (Milliken and Morrison, 2003), actually cause being disregard OS which can lead more serious problems (Perlow and Repenning, 2009: 195).

In their study aimed to determine why employees do not communicate with their managers, Milliken et al. (2003) revealed that big majority of the employees do not discuss organizational development issues with their boss, since they see it risky and redundant. Piderit and Ashford (2003) revealed that employees' speaking up about any concerns has potential risks for their images and credibility in the organization. 
Not only being understand why individuals remain silent is important for revealing unethical and illegal practices or its effects on effective organizational learning, but also interests them particularly within the context of staying in enterprise. Speaking up about issues is not without risks, but potential negative consequences of remain silent cause widespread devastation. Employees generally tend to avoid enlighten about organization when their managers demand these kind of information based on OS behaviour. This also means that essential knowledge is being distorted which is needed by the managers at decision making process (Milliken and Morrison, 2003: 1563, 1564). Premeaux and Bedeian (2003) emphasise that the concepts such as focus of control, self-esteem, top-management openness and trust in supervisor should be well-understood to break wall of silence. This is the best possible way to functionalize tacit knowledge which is needed for organizational development.

\subsection{The Relationship Between Psychological Empowerment and Organizational Silence}

Employees are the main source of change, creativeness, learning and innovations which are essential for organization success. Employee speaking up and/or using initiative about organizational issues and problems play a crucial role at organizational success. However, employees prefer to keep silent rather than speaking up in many organizations (Ehtiyar and Yanardağ, 2008: 52). Empowerment is an important determinant at preferring to speak up instead of silence behaviour. Because like all people, employees innately crave power and prestige as well. Moreover, anything that makes employee powerless is a destructive force (Appelbaum, Hebert and Leroux, 1999: 235). Contrary to this, perceiving empowerment increase voice (speaking up) behaviour as a result of feeling psychologically better and being more motivated toward empowerment. Hence, one of the assumptions of empowerment is that employees will speak up their ideas more actively when they are empowered (Spreitzer, 1996: 484). Both empowerment and silence behaviour are closely related with previous experiences. If any idea/suggestion of an employee do not take consider or present as a management's idea later on, employee will feel powerless and will prefer to keep his/her silent. Also, management approach to employees directly affects their PE perceptions and OS behaviours. In particular, considering employees only as a labour cost instead of investable resource increase those perceptions and behaviour much more (Smith and Mouly, 1998: 76-77).

Empowerment demands a willingness to embrace uncertainty, trust people and exercise faith (Quinn and Spreitzer, 1997: 45). If the management of an organization constitute any policies, strategies and culture that decrease powerless, this enhance not only feeling more responsibility for performing organizational duties but also contribute to concern organizational issues much more and personal development by speaking up. In other words, empowered employees behave more actively, take more initiatives and are more participative at carrying out organizational goals (Pelit, Öztürk and Arslantürk, 2011: 787). Chiang and Hsieh (2012) in their study concluded that employees who receives inadequate organizational support by hotel management, feel themselves worthless. Authors also suggest that management should take consider those employees' ideas and concerns in order to achieve pre-determined goals better. Moreover they propose that hotel managers must get employees' suggestions about work processes, departmental issues and organization policies to increase PE perception of their employees. And, they emphasize on the importance of this approach within the 
context of make the employees feel themselves worthy by being shared their ideas with the managers. Consequently, the authors state that hotel managers must get in contact with the employees and concern their ideas much more. By this, employees feel themselves worthier and important for the organization.

Enhancing all employees to give feedbacks, share knowledge and make suggestions is an efficient strategy in which the management should pursue, to gain favour from the employees' experiences, ideas and suggestions (Lashley, 1995: 29). Because empowered individuals can substantially affect their workmates and others (Thomas and Velthouse, 1990). They are also affected from work environment conditions. Work environment presents an atmosphere to employees which can increase or decrease their PE perceptions. Impact as a sub-dimension of PE is an important determinant within this atmosphere. Thus, employee's work oriented actions must have an effect on the results (Robbins, Crino and Fredendall, 2002: 423). By doing so, employee feel himself/herself empowered and get more involved in decision making process related with his/her work (Smith and Mouly, 1998: 74).

Empowerment includes risk taking, it opens the possibility of making mistakes. If those mistakes were punished, then individuals became disenchanted with their new way of thinking and regressed to past behaviors. In other words, employees' efforts to take initiative and risk must be reinforced rather than punished. If this support is missing or weak, employees worry about seeking permission before acting rather than asking for forgiveness in case they make mistakes. Empowered employees must feel that the people in their unit can work together to solve problems that employees ideas are valued and taken seriously (Quinn and Spreitzer, 1997: 45- 46).

PE is related with intrinsic motivation (Lashley, 1996: 335). Internally motivated individuals do not dependent on extrinsic factors such as rewards or recognitions given by management (Jha and Nair, 2008: 151). Thus psychologically empowered employees also empower their co-workers through their actions. Within this context they share success stories and help one another diagnose situations to develop efficient coping strategies (Quinn and Spreitzer, 1997: 45). Slattan and Mehmetoglu (2011) suggest that empowerment is linked to employee creativity, or the production of useful ideas (cited in: Mathe and Scott-Halsell, 2012: 358). Based on this, the following hypothesis was proposed:

$\boldsymbol{H}_{1}$ : PE applications have a significant effect on employees' OS attitudes in hotel enterprises.

As one of the sub-dimension of PE, meaning refers to the degree of employees' work goals fitting with their beliefs or values (Meng et al., 2016: 105). The key differences of group heterogeneity are based on beliefs/values. Individuals may share the main goals of organization, but they may differentiate in case of their beliefs about which policies are the most effective. Furthermore, though their beliefs are the similar, their preferences may differ (Banerjee and Somanathan, 2001: 190). To have work goals of individuals in keeping with their beliefs and values are also related to their perceptions of their own or their colleagues' positions within the organization. Individuals commonly don't unveil their psychology when facing with different treatments as if they were treated differently from others. This awareness may lead to review work goals due to perception of injustice. 
Pinder and Harlos (2001) emphasize that silence is an action that is active, consciously and intentionally and this consciously action also generates a systematic culture of silence in organizations. PE has a crucial role in transformation of this intentionally and consciously action to speaking up behaviors instead of silence. Empowered employees feel a sense of responsibility as they believe what they are doing is important to them (Quinn and Spreitzer, 1997: 41). The intrinsic responsibilities of employees in relation to given tasks (Thomas and Velthouse, 1990: 672) come out as a result of relationship between in question tasks and beliefs/values of employees. If this relationship is powerful, employees may avoid themselves from silence behaviors. So, it is assumed that;

\section{$\boldsymbol{H}_{1 a}$ : Meaning sub-dimension of PE perceptions of hotel employees has a significant effect on their OS attitude.}

Competence is related with self-efficacy. High-self efficacy generally results with initiatives, high performance and resistance to problems (Thomas and Velthouse, 1990). According to Bandura (1989), self-efficacy is required by a particular situation and it is associated with individual's belief about skills that drive his/her motivation, cognitive resources and course of action (cited in Amenumay and Lockwood, 2008). Empowered employees' motivation is higher than others. Those employees motive much more with intrinsic motives rather than extrinsic ones. However OS behaviour is largely caused by extrinsic motives. On the other hand, highly self-sufficient individuals' OS exhibiting rate is lower to others, since they do not affected by extrinsic motives. Further, managers' fear about employees' negative feedbacks is another source for OS (Morrison and Milliken, 2000). Based on this, managers behave in restrictive manner about using organizational resources. As a result, employees feel more powerless and exhibit more OS. From that, it is assumed that;

$\boldsymbol{H}_{1 b}$ : Competence sub-dimension of PE perceptions of hotel employees have a significant effect on their OS attitude.

Empowerment is a psychological situation involving relevant skills, control and authority senses of employees that provide them to pursue organizational activities aiming a more sustainable structure (Mondros and Wilson, 1994: 228). By extension, PE refers employees' self-perceptions about their reactions toward work conditions (Meng et al., 2016: 104). Employees innately desire a transparent work atmosphere in which they can react with their free will in case of positive/negative situations. In other words, employees demand a kind of autonomy in the organization that they can clearly express their ideas and concerns. And, providing to employees this kind of autonomy is closely related with organizational trust. Hence, trust on employee is an antecedent for the behavior that enables him/her to have autonomy (Robbins et al., 2002: 422).

Lashley (2001: 11) interprets empowerment as a "win-win" strategy that enables employees' commitment to organizational goals. Hereunder, employers could have committed and acknowledged staff whereas the employees get more satisfied with the work by using their abilities and skills, owing to empowerment. In this learning atmosphere employees improve themselves and develop sense of responsibility and authority. Employers, on the other hand, overcome work related difficulties and benefit from the productivity and low turnover rate by taking advantage of employees' experiences and ideas. At this point, active participating to decisions leading employee 
satisfaction through empowerment in which improves their self-efficacy and enable power requirement.

Employees' participation to strategic decisions with their ideas is essential for empowerment and for establishes a more efficient open communication channel. Although organizational voice is an important source of organizational change, employees behave reluctant about speaking up their ideas and concerns named as OS. And, OS destruct the organizational structure slowly that normally should be built on a sound basis. Destruction of organizational structure can also impair social solidarity. In addition, this kind of destruction impairs social and task exchange, which can also end up with self-efficacy diminishing. But, an individual can become empowered when he/she digress from OS within the context of ability to speak up his/her ideas (Bowen and Blackmon, 2003: 1393). Kahya (2015: 29) emphasize that individuals who have high degree of self-determination can set more strong goals since they meet their expectations. Individuals who can coincide their expectations with the organizational goals will be able to easily speak up any concerns that they surface in work. Thus, it can be assume that self-determination as a sub-dimension of PE decrease OS behavior. From this point of view we proposed following hypothesis:

$\boldsymbol{H}_{1 c}$ : Self-determination sub-dimension of PE perceptions of hotel employees has a significant effect on their OS attitude.

Individuals should be helped to feel themselves to be empowered. This approach reflects the fundamental philosophy of the organizations that embrace Grassroots model. Although Grassroots notion mostly identified with organizational policy, it also provides essential hints about PE in which the hotel management's efforts should be focus on. Because positional differences cause serious problems among employees in hotel enterprises. Hence, as soon as the power distinguish from executives' pressure, then equally distribute and share, it can pioneer employees' avoidance behaviour from OS, in hotel enterprises. Figures that are perceived as the owner of the power and the source of resisting the change as formal authorities are the main target of this effort (Mondros and Wilson, 1994: 229).

An empowered organization should be consider such a well-organized construct that can response environmental changes rapidly and can gain the maximum benefits from employees' strengths (Lashley, 2001: 10). The members of this construct can be entitled as the main source of the power (Mondros and Wilson, 1994: 229). Employees who responsible for service production have higher impact on customer related decisions. Thus, the more autonomy and responsibility is needed at service atmosphere (Wilkinson, 1998: 47). Robbins, Crino and Fredendall (2002: 42) state that employees' competence feeling is particularly related with the opportunities about using organizational resources efficiently. Therefore employees' impact skills on strategic decisions and their perceptions about the possibility of its realization can result with the decrease at OS behaviours. People believe that they can have influence on their work unit; others listen to their ideas (Quinn and Spreitzer, 1997: 41). Employees must believe that their behaviour will have some influence on what happens in this environment (Robbins, Crino and Fredendall, 2002: 422). In accordance with the given information, the fourth sub-hypothesis of the study is;

$\boldsymbol{H}_{1 d}$ : Impact sub-dimension of PE perceptions of hotel employees has a significant effect on their OS attitude. 
In the light of conceptual framework, mentioned relation between PE and OS, and the given justifications emphasizing the effects of PE on OS, the model of the study is set as presented below.

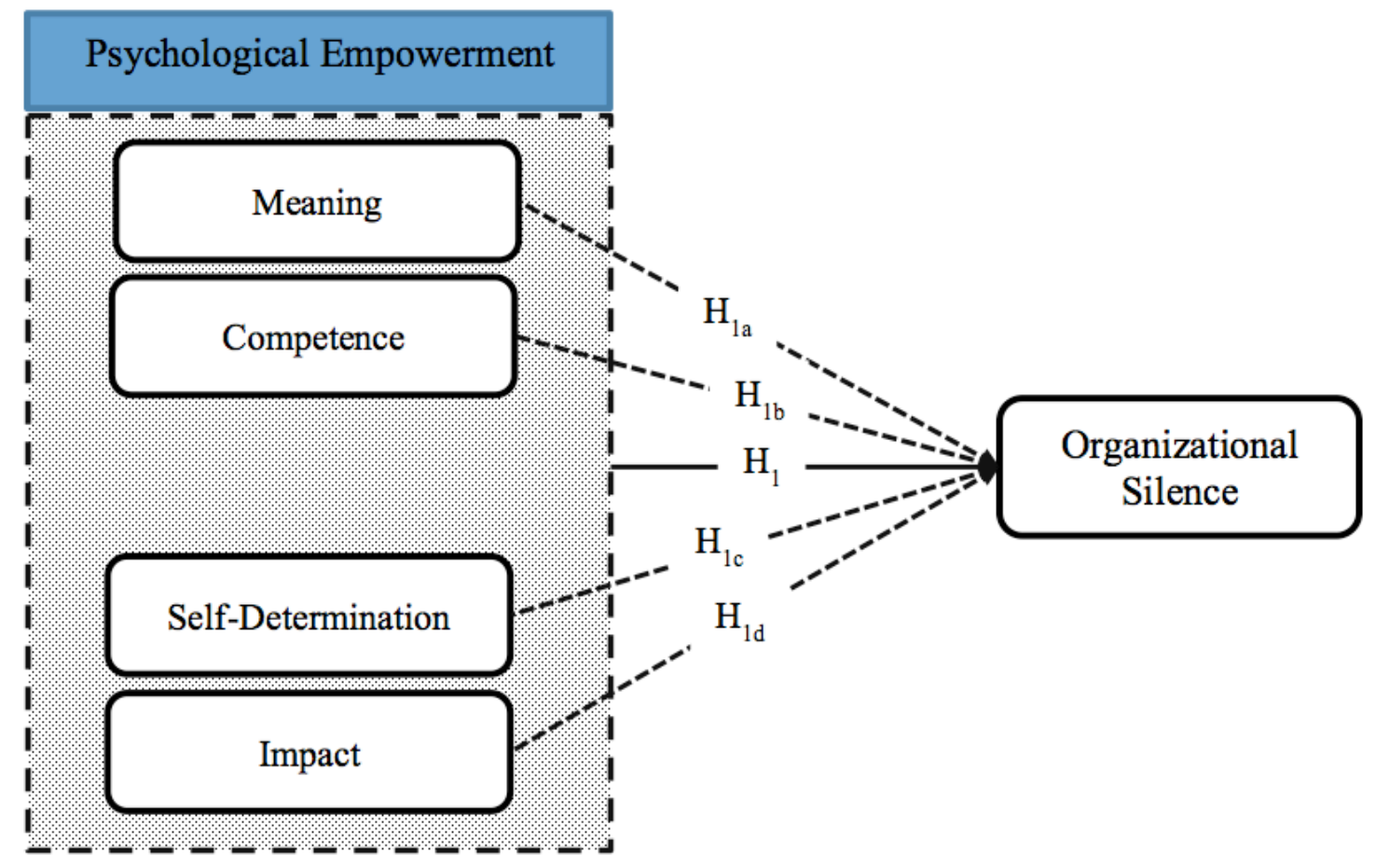

Figure 1: Research Model and Hypothesis

\section{Methodology}

This study aims to assign the effects of PE practices on employees' OS attitudes. Within this scope, data collected from five-star hotels operating in Antalya. By random sampling 420 hotel staff have been chosen as the sample of this study and relevant data gathered by questionnaire technique. Although random sampling was used in the study, a big proportion of participants were the trainees who attended "On the job training courses" organized by the Ministry of Culture and Tourism. By the way 348 of 420 forms are used for the analysis after extracting of some questionnaires incomplete and incorrect information.

Questionnaire form used in the study is basically consisting of three main sections. The first section of the form includes eight closed-ended questions measuring some demographics of participants (gender, group of age, marital status, educational background, monthly income, tenure at the hotel and sector). The second section of the questionnaire consist twelve statements referring OS, while other twelve statements referring PE take part at the last section. At this point, OS scale adapted from Erenler (2010) and Spreitzer's scale (1995) is used to measure PE of participants. 5 point Likert Scale is used for both two scales ranging from "Strongly Disagree" to "Strongly Agree" in accordance with the aim of study.

\subsection{Data Analysis}

Data analysis process of the study mainly includes Reliability Analysis, descriptive analysis (frequency and percentages, mean, standard deviation) and, Correlation and Regression analysis. Firstly, Reliability Analysis was conducted in 
order to measure whether relevant data was suitable for further analysis. Cronbach's Alpha coefficient indicating reliability was measured 0.844 for overall scale and 0.859 for OS while it was 0.923 for PE. Thus it is concluded that data set is reliable and suitable for further analysis.

Table 1: Demographic characteristics of participants

\begin{tabular}{|c|c|c|c|c|c|c|c|}
\hline \multirow{2}{*}{ Variable } & \multirow{2}{*}{ Sub-dimensions } & \multicolumn{2}{|c|}{ Total } & \multirow{2}{*}{ Variable } & \multirow{2}{*}{ Sub-dimensions } & \multicolumn{2}{|c|}{ Total } \\
\hline & & $\mathrm{n}$ & $\%$ & & & $\mathrm{n}$ & $\%$ \\
\hline \multirow{3}{*}{ Gender } & Female & 93 & 26,7 & \multirow{6}{*}{$\begin{array}{l}\text { Tenure in } \\
\text { Tourism }\end{array}$} & $\ldots \ldots \leq 1$ year & 56 & 16,1 \\
\hline & Male & 251 & 72,1 & & $2-4$ years & 116 & 33,3 \\
\hline & System & 4 & 1,2 & & 5-7 years & 76 & 21,8 \\
\hline \multirow{6}{*}{$\begin{array}{l}\text { Group of } \\
\text { Age }\end{array}$} & $18-22$ ages & 41 & 11,8 & & $8-10$ years & 28 & 8,0 \\
\hline & 23-27 ages & 127 & 36,5 & &..$\geq 11$ years & 66 & 19,0 \\
\hline & $28-32$ ages & 78 & 22,4 & & System & 6 & 1,8 \\
\hline & 33-37 ages & 40 & 11,5 & \multirow{6}{*}{$\begin{array}{l}\text { Tenure in } \\
\text { Current hotel }\end{array}$} & $\ldots \ldots \leq 1$ year & 115 & 33,0 \\
\hline & Over 37 ages & 61 & 17,5 & & $2-4$ years & 132 & 37,9 \\
\hline & System & 1 & 0,3 & & $5-7$ years & 42 & 12,1 \\
\hline \multirow{3}{*}{$\begin{array}{l}\text { Marital } \\
\text { Status }\end{array}$} & Single & 146 & 42,0 & & $8-10$ years & 8 & 2,3 \\
\hline & Married & 200 & 57,5 & &..$\geq 11$ years & 46 & 13,2 \\
\hline & System & 2 & 0,6 & & System & 5 & 1,4 \\
\hline \multirow{5}{*}{ Education } & Primary & 56 & 16,1 & \multirow{8}{*}{$\begin{array}{l}\text { Department } \\
\text { of working }\end{array}$} & Front office & 96 & 27,6 \\
\hline & Secondary & 171 & 49,1 & & $\mathrm{~F} \& \mathrm{~B}$ & 143 & 41,1 \\
\hline & Higher & 119 & 34,2 & & Housekeeping & 57 & 16,4 \\
\hline & System & 2 & 0,6 & & HRM & 3 & ,9 \\
\hline & $\ldots \ldots \leq 600$ & 37 & 10,6 & & $\mathrm{PR}$ & 8 & 2,3 \\
\hline Monthly & $601-1000$ & 156 & 44,8 & & Sales \& Marketing & 7 & 2,0 \\
\hline Income & $1001-1400$ & 100 & 28,7 & & Other & 32 & 9,2 \\
\hline (Turkish & $1401-1800$ & 29 & 8,3 & & System & 2 & 0,6 \\
\hline
\end{tabular}

Liras) $\ldots . . \geq 1801$

$20 \quad 5,7$

System 1,8

Some demographic characteristics of participants (n: 348) were analysed with frequency and percentage techniques after confirming data set's reliability. According to results presented in Table 1, a great majority of participants by scoring $72.1 \%$ total are male. Nearly half of the participants are under 27 ages (n: 168, 48.3\%) meanwhile $57.5 \%$ of them are married. At least 119 participants are graduated from university by consisting $34.2 \%$ of total. Further almost half of participants have secondary school diploma. Contrary to their well education level, monthly incomes statistics indicate that most of the participants are working earn less than 1401 TL.

Within the context of participants tenure in tourism, there two main group which can be named as beginners and well-experienced ones in reference to results in Table 1. Beginners who have been working less than 5 years constitute $49.4 \%$ of total while experienced ones constitute 27.0 of total with the experiment more than 7 years. On the other hand, 33\% of participants have been working at their current hotel at most 1 year or less than 1 year. $37.9 \%$ of participants have from two to four years experiment at the same enterprises. Finally F\&B (n: 143, 41.1\%), Front Office (n: 97, 27.6\%) and Housekeeping (n: $57,16.4 \%$ ) are three major departments among others counted in the study. 


\section{Findings}

In accordance with aim of the study, firstly the relation between PE and OS is tested with Correlation Analysis as presented in Table 2. With reference to Correlation Analysis, there is a weak but statistically significant relationship between PE and OS (r: 0.107, p: 0.045). Thus, it can be assumed that PE applications applied by hotel management could have an impact on employees' OS attitude.

Table 2: Mean, Standard Deviations, and Correlations

\begin{tabular}{|c|c|c|c|c|c|c|c|c|c|}
\hline & $\bar{x}$ & s.d. & & OS & PE & PEM & $P E C$ & $P E D$ & $P E I$ \\
\hline $\begin{array}{l}\text { Organizational Silence } \\
\text { (OS) }\end{array}$ & 3,483 & 0,815 & $\begin{array}{l}r \\
p\end{array}$ & 1 & & & & & \\
\hline $\begin{array}{l}\text { Psychological Empowerment } \\
\text { (PE) }\end{array}$ & 3,902 & 0,782 & $\begin{array}{l}r \\
p\end{array}$ & $\begin{array}{l}0,107^{*} \\
0,045\end{array}$ & 1 & & & & \\
\hline $\begin{array}{l}P E \\
\qquad \text { Meaning (PEM) }\end{array}$ & 4,249 & 1,025 & $p$ & $\begin{array}{l}0,100 \\
0,061\end{array}$ & $\begin{array}{l}0,801^{* *} \\
0,000\end{array}$ & 1 & & & \\
\hline $\begin{array}{l}P E \\
\qquad \text { Competence }(P E C)\end{array}$ & 4,218 & 918 & $p$ & $\begin{array}{l}0,072 \\
0,179 \\
\end{array}$ & $\begin{array}{c}0,831^{* *} \\
0,000\end{array}$ & $\begin{array}{l}0,752^{* *} \\
0,000 \\
\end{array}$ & 1 & & \\
\hline $\begin{array}{l}P E \\
\quad \text { Self-Determination (PED) }\end{array}$ & 3,707 & ,966 & $p$ & $\begin{array}{l}0,140^{* *} \\
0,009\end{array}$ & $\begin{array}{l}0,820^{* *} \\
0,000\end{array}$ & $\begin{array}{l}0,441^{* *} \\
0,000\end{array}$ & $\begin{array}{l}0,562^{* *} \\
0,000 \\
\end{array}$ & 1 & \\
\hline $\begin{array}{l}P E \\
\quad \text { Impact (PEI) }\end{array}$ & 3,432 & 1,015 & $\begin{array}{l}r \\
p\end{array}$ & $\begin{array}{l}0,032 \\
0,556\end{array}$ & $\begin{array}{c}0,742^{* *} \\
0,000\end{array}$ & $\begin{array}{c}0,361^{* *} \\
0,000\end{array}$ & $\begin{array}{c}0,363^{* *} \\
0,000\end{array}$ & $\begin{array}{l}0,624^{* *} \\
0,000\end{array}$ & 1 \\
\hline $\begin{array}{l}\text { *. Correlation is significant at th } \\
\text { **. Correlation is significant at } \\
\text { r. Pearson Correlation, p. Sig (2 }\end{array}$ & $\begin{array}{l}\text { the } 0.05 \\
\text { thailed) }\end{array}$ & $\begin{array}{l}\text { level (2 } \\
\text { level } \\
\text { Note: }\end{array}$ & -tai & $\begin{array}{l}\text { led). } \\
\text { ailed). } \\
\text { items we }\end{array}$ & ere reve & e code & in the s & & \\
\hline
\end{tabular}

Based on the observed relationship between PE and OS, Correlation Analysis was performed with sub-dimensions of PE and OS. Contrary to expectations, only selfdetermination sub-dimension of PE has relationship with OS (r: 0.140, p: 0.009), while other sub-dimensions of PE do not have any significant relationship with OS.

With reference to observed relationship between PE and OS, Regression Analysis was performed to determine whether PE applications have any significant effect on the OS attitude of participants. And, Univariate Regression Analysis was used at this phase. Since, it is hypothesised that OS attitude of employees is significantly affected from PE applications, OS considered as dependent variable during analysis process, meanwhile $\mathrm{PE}$ and its sub-dimensions considered as independent variable. Although results in Table 3 confirm the significant effect of PE on OS attitude, standardized beta values indicates that this effect is very weak $(\beta$ : 0.107). Hence, each increment in PE perceptions decreases OS only at the rate of 0.10 . Anyway these results imply that first hypothesis of the study referring "PE applications have a significant effect on employees' OS attitudes." is supported. Namely, PE applications sustaining in hotel enterprises partially affect OS attitude of hotel employees.

Table 3: Univariate Regression Analysis

\begin{tabular}{ccccccc}
\hline $\begin{array}{c}\text { Independent } \\
\text { variable }\end{array}$ & $\begin{array}{c}\text { Dependent } \\
\text { variable }\end{array}$ & $\boldsymbol{\beta}$ & $\boldsymbol{R}^{2}$ & $\begin{array}{c}\text { Adjusted } \\
\boldsymbol{R}^{2}\end{array}$ & $\begin{array}{c}\boldsymbol{F} \\
\text { value }\end{array}$ & Sig. \\
\hline $\begin{array}{l}\text { Psychological } \\
\text { Empowerment }\end{array}$ & $\begin{array}{c}\text { Organizational } \\
\text { Silence }\end{array}$ & 0.107 & 0.012 & 0.009 & 4.041 & $0.045^{*}$ \\
\hline
\end{tabular}

Note: Entries are standardized beta coefficients, $N=211$ 
In the on-going process, more detailed Regression Analysis was conducted by considering that sub-dimensions of PE could significantly affect OS. Contrary to our assumptions, it is observed that only self-determination sub-dimension of PE has significant effect on OS attitude of employees $(\beta: 0.1206$, p: 0.008$)$, while other subdimensions do not have significant effect on OS ( $>00.005$ ). Thus, $H_{l a}, H_{l b}$ and $H_{l d}$ hypothesis of the study were rejected. However, $H_{l c}$ hypothesis was supported with reference to observed significance values $(\mathrm{p}<0.05)$ and $\beta$ values in Regression Analysis. In other words, self-determination sub-dimension of PE applications sustaining in hotel enterprises significantly affect the OS attitude of hotel employees. But, it should be noted that this affect is weak $(\beta: 0.206)$. As a result of this, each increment in selfdetermination PE perceptions decreases OS attitude at the rate of 0.21 .

Table 4: Multivariate Regression Analysis

\begin{tabular}{|c|c|c|c|c|c|}
\hline & \multicolumn{2}{|c|}{$\begin{array}{c}\text { Unstandardized } \\
\text { Coefficients }\end{array}$} & \multirow{2}{*}{$\begin{array}{c}\begin{array}{c}\text { Standardized } \\
\text { Coefficients }\end{array} \\
\text { Beta } \\
\end{array}$} & \multirow[t]{2}{*}{$t$} & \multirow[t]{2}{*}{ Sig. } \\
\hline & B & Std. Error & & & \\
\hline (Constant) & 3,081 &, 223 & & 13,797 & $0,000 * *$ \\
\hline PE meaning &, 094 &, 065 &, 118 & 1,452 & 0,147 \\
\hline$P E$ competence &,- 084 &, 078 &,- 094 & $-1,075$ & 0,283 \\
\hline$P E$ self-determination &, 174 & 065 & 206 & 2,689 & $0,008 * *$ \\
\hline PE impact &,- 085 &, 055 &,- 105 & $-1,533$ & 0,126 \\
\hline$R: 0.175$ & & Adjusted $R^{2}:$ & $F V a$ & $e: 2,702$ & p: $0.031^{*}$ \\
\hline
\end{tabular}

In sum, both Correlation and Regression Analysis indicate that PE applicants in hotel enterprises have a significant effect on OS attitude displayed by hotel employees. Further this effect is relatively weak in general and also can observe on selfdetermination sub-dimension of PE.

\section{Conclusions}

In today's organizations, efficient competitive strategies basically depend on innovative initiatives and the quality of intellectual capital. Besides, both these two determinants could have an effect on competition only if the employees can make work processes distinctive and superior by speaking up and implying their innovative ideas which are also able to be core competences of any company. Empowerment is one of the efficient ways to get employees' precious work ideas/concerns or suggestions for organizations health and sustainability. As long as the organizations empower their staff, they probably keep their innovative structure which is a means of successful competition. In the contrary case, employees would prefer keep their silent which is also called as OS. In that empowerment circumstantially should be related with OS. When their conceptual origins are examined, it is assumed that there is an inverse relationship between PE activities and OS behaviors. In other words, if PE practices of an organization increases, OS would decrease in the same manner. Because one of the assumption of empowerment is employees' speaking up tendencies in higher volumes of their opinions which are likely effecting and shaping organizational activities (Spreitzer, 1996: 484). Empowered participants may affect their associates through proactive behaviors (Thomas and Velthouse, 1990). Within this context they can share success stories and can help one another diagnose situations to develop appropriate coping strategies (Quinn and Spreitzer, 1997: 45).

In the study, relationship between PE and OS, and possible effects of PE on OS were studied within the context of hotel enterprises. Correlation Analysis results 
confirmed that there is a statistically significant relationship between PE and OS. Moreover, PE has a significant but relatively slender effect on OS behaviours. Also, in detailed analysis it is concluded that self-determination sub-dimension of PE have positive effects on OS behaviours. The facts remain that meaning, competence, and impact sub-dimensions of PE do not have any significant effects on OS behaviours. According to our knowledge, there is not any study which directly researches the relationships between PE and OS. Thus, it is difficult to compare the results of our study with similar studies due to their absence. At one of limited studies related with OS, Milliken et al. (2003) concluded that young and inexperienced workers assigning at top management or workers who are assigning at lower organizational positions, have higher possibilities of surfacing the adverse outcomes of OS, because of their perceptions towards they have less impact in the organization.

As mentioned before, a significant relationship was determined between selfdetermination sub-dimension of PE and OS behaviour. Hotel activities mostly carry out under the interaction of customer and staff. At this point, using initiatives of any employee is essential within the context of employee's mobilization (high quality service). Thus, we assume that this is the main reason in which high mean scores were calculated at self-determination sub-dimension. Because, empowerment is a psychological situation involving relevant skills, control and authority senses of employees that provide them to pursue organizational activities aiming a more sustainable structure (Mondros and Wilson, 1994: 228). In addition PE refers employees' self-perceptions about their reactions toward work conditions (Meng et al., 2016: 104). Furthermore, Kahya (2015: 29) emphasize that individuals who have high degree self-determination can set more strong goals since they meet their expectations. Individuals who can coincide their expectations with the organizational goals will be able to easily speak up any concerns that they surface in work.

Hotel enterprises involved in the study are generally are seasonal enterprises. Additionally employee turnover rates are relatively high at those enterprises. Considering this fact, participants as the employees of those hotels could perceive their job unimportant and temporary. Therefore, they can both see their job as temporary or nonsense and do not speak up their innovative ideas, even if their empowerment perceptions are very high. For this reason, we assume that there is no direct relationship between meaning and OS.

Being operated with all-inclusive concept of the hotels contributed to study downgrades service processes; correspondingly minor and standardized services render at those hotels. As a result, they operate with non-innovative work processes based on scalar relationships (chain of command). Hence, employees who are also competent and have an impact potential in the context of PE think that their ideas or concerns are not important even if they speak up those ideas or concerns. So, we assume that employees consider any empowerment efforts through competence and impact independent from organizational voice or silence.

Above all, perceiving empowerment as increase voice (speaking up) behavior as a result of feeling psychologically better and being more motivated toward empowerment. Hence, one of the assumptions of empowerment is that employees will speak up their ideas more actively when they are empowered (Spreitzer, 1996: 484). So, in today's business, $\mathrm{PE}$ is one the most popular approach towards management of organizational 
courses. Because no one can be expert on any work as much as the one who do it. Thus, allowing the employees to take initiatives on work related decisions will enable them to perform their works more productively and efficient. Employees who have the sense of empowerment will be more concerned on their works, department and the company, and they will actively involve decision processes, in that they will speak up more and more.

This study subjecting PE and OS has some limitations in the context of its methodology and findings. First of all, this study was conducted only at Antalya, thus it was unable to compare any possible differences about the effects of PE on OS. Secondly, there is a limited discussion about the results, considering the fact that the absence of any similar studies directly addressing PE and OS. Gathering relevant data with only questionnaire technique is another limitation of this study. Hence, it was unable to validate the findings with interviews. Although its limitations, this study could be a pioneer for future studies. Thus, more detailed and comprehensive studies should be conduct in the future.

\section{References}

Amenumay, E. K. and Lockwood, A. (2008). Psychological Climate and Psychological Empowerment: An Exploration in a Luxury UK Hotel Group. Tourism and Hospitality Research, 8 (4), 265-281.

Appelbaum, S.H., Hebert, D., and Leroux, S. (1999). Empowerment: Power, Culture and Leadership-A Strategy or Fad for the Millennium?, Journal of Workplace Learning: Employee Counselling Today, 11 (7), 233-254.

Banerjee, A. and Somanathan, R. (2001). A Simple Model of Voice. The Quarterly Journal of Economics, February, 189-227.

Beer, M. and Eisenstat, R. A. (2000). The Silent Killers of Strategy Implementation and Learning. Sloan Management Review, Summer, 29-40.

Bowen, F. and Blackmon, K. (2003). Spirals of Silence: The Dynamic Effects of Diversity on Organizational Voice. Journal of Management Studies, 40 (6), p. 1393-1417

Chan, Y. H., Taylor, R. R., and Markham, S. (2008). The Role of Subordinates' Trust in a Social Exchange Driven Psychological Empowerment Process, Journal of Managerial Issues, 20 (4), 444-467.

Chiang, C. F. and Hsieh, T. S. (2012). The Impacts of Perceived Organizational Support and Psychological Empowerment on Job Performance: The Mediating Effects of Organizational Citizenship Behavior. International Journal of Hospitality Management, 31 (1), 180-190.

Conger, J. A., (1989). Leadership: The Art of Empowering Others. The Academy of Management Executive, 3 (1), 17-24.

Conger, J. A., and Kanungo, R. N., (1988). The Empowerment Process: Integrating Theory and Practice. Academy of Management Review, 13 (3), 471-482.

Corsun, D. L. and Enz C. A. (1999). Predicting Psychological Empowerment among Service Workers: The Effect of Support-Based Relationships. Human Relations, $52(2), 205-224$. 
Demir, M. (2014). İşgörenlerin Adalet Algılamaları Kapsamında Sessizlik Davranışının Kariyer Beklentisi ile İlişkisi. International Journal of Human Sciences, 11 (1), 1095-1113.

Ehtiyar, R., and Yanardağ, M. (2008). Organizational Silence: A Survey on Employees Working in a Chain Hotel. Tourism and Hospitality Management, 14 (1), 51-68.

Erenler, E. (2010). Çalışanlarda Sessizlik Davranışının Bazı Kişisel ve Örgütsel Özelliklerle İlişkisi: Turizm Sektöründe Bir Alan Araştırması, (Yayınlanmış Doktora Tezi). Hacettepe Üniversitesi Sosyal Bilimler Enstitüsü, Ankara.

Gkorezis, P. Hatzithomas, L. and Petridou, E. (2011). The Impact of Leader's Humor on Employees' Psychological Empowerment: The Moderating Role of Tenure. Journal of Managerial Issues, 23 (1), 83-95.

Guchait, P., Madera, J. and Dawson, M. (2016). Learning in the Service Environment: The Influence of Diversity Climate. Journal of Service Theory and Practice, 26 (4), 448-470.

Hancer, M., and George, R.T., (2003). Psychological Empowerment of NonSupervisory Employees Working in Full-Service Restaurants. Hospitality Management, 22, 3-16.

Jha, S.S., and Nair, S.K, (2008). Influence of Locus of Control, Job Characteristics and Superior-Subordinate Relationship on Psychological Empowerment: A Study in Five Star Hotel. Journal of Management Research, 8 (3), 147-161.

Kahya, C. (2015). Mesleki Özyeterlilik ve Örgütsel Sessizlik İlişkisini Belirlemeye Yönelik Ampirik Bir Çalışma. Çankırı Karatekin Üniversitesi İktisadi ve İdari Bilimler Fakültesi Dergisi, 5 (1), 293-314.

Kim, B (P)., Lee, G., Murrmann, S. K., and George, T. R. (2012). Motivational Effects of Empowerment on Employees' Organizational Commitment: A Mediating Role of Management Trustworthiness. Cornell Hospitality Quarterly, 53 (1), 1019.

Kish-Gephart, J. J., Detert, J. R., Trevino, L. K. and Edmondson, A. C. (2009). Silenced by Fear: The Nature, Sources, and Consequences of Fear at Work. Research in Organizational Behavior, 29, 163-193.

Klagge, J. (1998). The Empowerment Squeeze-Views from the Middle Management Position. Journal of Management Development, 17 (8), 548-558.

Koyuncu, M., Burke, R., Fixenbaum, L. and Tekin, Y. (2013). Antecedents and Consequences of Employee Voice Behaviour among Front-line Employees in Turkish Hotels. Anatolia-An International Journal of Tourism and Hospitality Research, 24 (3), 427-437.

Lashley, C. (1995). Towards an Understanding of Employee Empowerment in Hospitality Services. International Journal of Contemporary Hospitality Management, 7 (1), 27-32.

Lashley, C. (2001). Empowerment: HR Strategies for Service Excellence. Oxford: Butterworth \& Heinemann. 
Mathe, K. and Scott-Holsell, S. (2012). The Effects of Perceived External Prestige on Positive Psychological States in Quick Service Restaurants. Journal of Human Resources in Hospitality \& Tourism, 11 (4), 254-372.

Meng, L., Jin, Y. and Guo, J. (2016). Mediating and/or Moderating Roles of Psychological Empowerment. Applied Nursing Research, 30, 104-110.

Menon, S. T., (2001). Employee Empowerment: An Integrative Psychological Approach. Applied Psychology: An International Review, 50 (1), 153-180.

Milliken, F. J. and Morrison, E. W. (2003). Shades of Silence: Emerging Themes and Future Directions for Research on Silence in Organizations. Journal of Management Studies, 40 (6), 1563-1568.

Milliken, F. J., Morrison, E. W. and Hewlin, P. F. (2003). An Exploratory Study of Employee Silence: Issues that Employees Don't Communicate Upward and Why? Journal of Management Studies, 40 (6), 1453-1476.

Mondros, J. B. and Wilson, S. M. (1994). Organizing for Power and Empowerment. New York: Columbia University Press.

Morrison, E. W. and Milliken, F. J. (2000). Organizational Silence: A Barrier to Change and Development in a Pluralistic World. The Academy of Management Review, 25 (4), 706-725.

Pelit, E., Öztürk, Y. and Arslantürk, Y. (2011). The Effects of Employee Empowerment on Employee Job Satisfaction: A Study on Hotels in Turkey. International Journal of Contemporary Hospitality Management, 23 (6), 784-802.

Perkins, D. D. and Zimmerman, M. A. (1995). Empowerment Theory, Research, and Application. American Journal of Community Psychology, 23 (5), 569-579.

Perlow, L. A. and Repenning, N. P. (2009). The Dynamics of Silencing Conflict. Research in Organizational Behavior, 29, 195-223.

Piderit, S. K. and Ashford, S. J. (2003). Breaking Silence: Tactical Choices Women Managers Make in Speaking Up About Gender-Equity Issues. Journal of Management Studies, 40 (6), 1477- 1502.

Pinder, C. C. and Harlos, K. P. (2001). Employee Silence: Quiescence and Acquiescence as Responses to Perceived Injustice. Research in Personnel and Human Resources Management, 20, 331-369.

Premeaux, S. F. and Bedeian, A. G. (2003). Breaking the Silence: The Moderating Effects of Self-Monitoring in Predicting Speaking Up in the Workplace. Journal of Management Studies, 40 (6), 1537- 1562.

Quinn, R. E., and Spreitzer, G. M., (1997). The Road to Empowerment: Seven Questions Every Leader Should Consider. Organizational Dynamics, 26 (2), 3748.

Robbins, T. L., Crino, M. D., and Fredendall, L. D. (2002). An Integrative Model of the Empowerment Process. Human Resource Management Review, 12, 419-443.

Smith, A. C., and Mouly, V. S., (1998). Empowerment in New Zealand Firms: Insights from the Cases. Empowerment in Organizations, 6 (3), 69-80. 
Spreitzer, G. M. (1995), Psychological Empowerment in the Workplace: Dimensions, Measurement, and Validation. Academy of Management Journal, 38 (5), 14421465.

Spreitzer, G. M. (1996). Social Structural Characteristics of Psychological Empowerment. Academy of Management Journal, 39 (2), 483-504.

Spreitzer, G. M., Kizilos M. A, and Nason, S. W., (1997). A Dimensional Analysis of the Relationship between Psychological Empowerment and Effectiveness, Satisfaction, and Strain. Journal of Management, 23 (5), 679-704.

Spreitzer, G. M., De Janasz, S. C. and, Quinn, R. E. (1999). Empowered to Lead: The Role of Psychological Empowerment in Leadership. Journal of Organizational Behavior, 20, 511-526.

Thomas, K. W., and Velthouse, B. A. (1990). Cognitive Elements of Empowerment: An "Interpretive" Model of Intrinsic Task Motivation. Academy of Management Review, 15 (4), 666-681.

Van Dyne, L., Ang, S. and Botero, I. C. (2003). Conceptualizing Employee Silence and Employee Voice as Multidimensional Constructs. Journal of Management Studies, 40 (6), 1359- 1392.

Wilkinson, A. (1998). Empowerment: Theory and Practice. Personnel Review, 27 (1), 40-56.

Zhou, J. and George, J. M. (2001). When Job Dissatisfaction Leads to Creativity: Encouraging the Expression of Voice. Academy of Management Journal, 44 (4), 682-696. 